\title{
Development of model based sensors for the supervision of a solar dryer
}

\author{
E. Correa-Hernando ，F.J. Arranz , B. Diezma , E. Juliá , J.I. Robla ，L. Ruiz-Garcia , J. García-Hierro , \\ P. Barreiro
}

Departamento de Ciencia y Tecnologia Aplicadas a la ingeniería Técnica Agrícola, Escuela Universitaria de Ingeniería Técnica Agricola, Universidad Politécnica de Madizi, Av, Complutense s/n, 28040 Madrid, Spain

Departamento de ingeniería Rural, Escuela Técnica Superior de Ingenieros Agrónomos, Universidad Politécnica de Madrid, Av, Complutense s/n, 28040 Madrid, Spain

Grupo de Energías Renovables, Facuitad de Mecánica, Universidad de Oriente. Avenida Las Américas, Santiago de Cuba, Cubo

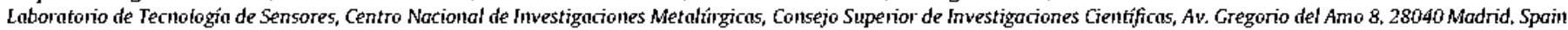

Keywords:

Ubiquitous monitoring

Psychrometric model

Automated control

Energy efficiency

Wood

Smart sensor

\begin{abstract}
A B S T R A C T
Solar dryers are increasingly used in developing countries as an alternative to drying in open air, however the inherent variability of the drying conditions during day and along year drive the need for achieving low cost sensors that would enable to characterize the drying process and to react accordingly. This paper provides three different and complementary approaches for model based sensors that make use of the psychrometric properties of the air inside the drying chamber and the temperature oscillations of the wood along day. The simplest smart sensor, SMART-1, using only two Sensirion sensors, allows to estimate the accumulated water extracted from wood along a complete drying cycle with a correlation coefficient of 0.97 . SMART- 2 is a model based sensor that relays on the diffusion kinetics by means of assesing temperature and relative humidity of the air inside the kiln. SMART-2 model allows to determine the diffusivity, being the average value of $D$ for the drying cycle studied equal to $5.14 \times 10^{10} \mathrm{~m}^{2} \mathrm{~s}^{1}$ and equal to $5.12 \times 10^{10} \mathrm{~m}^{2} \mathrm{~s}^{1}$ for two experiments respectively. The multidistributed supervision of the dryer shows up the lack of uniformity in drying conditions supported by the wood planks located in the inner or center of the drying chamber where constant drying rate kinetics predominate. Finally, sMART-3 indicates a decreasing efficiency along the drying process from 0.9 to 0.2
\end{abstract}

\section{Introduction}

Low cost sensors are most suitable for the supervision and control of solar dryers, and can be easily upgraded by including smart capabilities. According to Corsi (2007), the term smart sensor refers to those elements containing sensing and signal processing capabilities and understanding, with objectives ranging from simple viewing to sophisticated remote sensing, surveillance, search/ track, robotics, perceptronics and intelligence applications. The smart sensor is expected to have the capability that functionality and architecture, as well as raw data acquisition are based on the existence of a microprocessing unit (Son et al., 2009).

on board processing at the sensor allows a portion of the computation to be done locally on the sensors' embedded microprocessor, with self diagnosis and self-calibration capabilities, thus reducing that data amount of information that needs to be transmitted over the network. It is important to state that the basic difference between a smart sensor and a standard integrated sensor is its intelligence capabilities (Spencer et al., 2004).
More and more, intensive and real-time data acquisition networks point that it is feasible to reconstruct spatial information in large areas from relatively scarce local data, though there is a need for simultaneously engineer the application and the technology knowledge (Camilli et al., 2007), as well as bringing together engineering and agronomics (Kitchen, 2008).

lntegrating environmental data into model based concepts allow estimating risk of epidemic development in the fields even on a daily basis that can be web-based consulted (Wharton et al., 2008; Matese et al., 2009; Zhu et al., 2010), and can be used for more efficient closer-to-crop practices (Cunha et al., 2010) with closed loop on-site control of agricultural practices such as irrigation (Vellidis et al., 2008). Special requirements are found when wireless nodes are mounted on moving targets such as anima] (Nadimi et al., 2008; Umstätter et al., 2008; Tøgersen et al., 2010).

lnformation models can be centered on the decision maker for the generation of management systems, which will lead to new working habits and to gaining increased insight into their production processes, as well as to access and utilize better available scientific research and technological developments (Sorensen et al., 2010).

Wood drying is an important step in wood manufacturing and the highest energy consumer with about $70 \%$ of the total energy 
used in the manufacturing of most wood products (Khater et al., 2004). Since the 1960 s, several types of solar kiln for timber drying have been studied and improved on, due to some advantages of the solar kilns, as lower or no operating cost since no fuel is needed for air heating. On the other hand the main disadvantage is its dependence on weather conditions resulting in less controllability by the operator, and less predictable outcomes (Haque and Langrish, 2005: Reuss et al., 1997). Commercial kilns (i.e. Solar Dryers Australia Pty. Ltd. or CONA SOLAR AUSTRIA) are available, ranging from very simple systems with only a solar kiln with an integrated collector and small capacity, to automated dryers with an integrated energy storage system.

In some solar dryers, the product to be dried receives energy not only from the hot air supplied by a solar collector but by direct exposure to solar radiation, being the product protected from rain, insects and dust (Fargali et al., 2008). One of the functions of the closed-type solar dryers is to avoid and isolate the humid environment from the drying process, including sometimes a dehydrator unit to enhance the drying process and to reuse the hot air. Other types of solar dryers make use of a solar collector that utilizes directly the energy from the sun to heat water that passes through it (Fargali et al., 2008). In such case, the output water from the collector is stored in a water tank. Such dryers attenuate the effect of solar radiation variability along the day, due to cloudy conditions, as well as due to the absence of radiation during night.

According to Chen et al. (2005), in traditional open-sun drying methods the drying rate is controlled by a number of external factors (solar radiation, ambient temperature, wind velocity and relative humidity) and internal factors (initial moisture content, type of product, and the mass of product per unit exposed area). Such procedure, does not allow for obtaining a suitable and reproducible product quality, especially for food, mainly because of the inherent limitations in controlling the drying process.

Recently, Luna et al. in a review on the trends in solar kilns for drying timber uses an analytical method for product design based on TRIZ theory (Luna et al., 2009), and proposes the use of eight laws to evaluate developments in solar dryers. Two of such laws, Coordination of Rhythms and Increase in Level of improvement, are specially defined to solve problems caused by the alternating day/night, stacional rythms or weather variations. The gujdelines of this article can help addressing the quality of any dryer design. The definition, implementation and integration of intelligent model based sensors in solar dryers, which is faced in current research work actively enhances the quality of the dryer design.

\section{Materials and methods}

\subsection{Solar dryer}

An experimental solar dryer, constructed by CONA SOLAR (Austria) and sited in Cuba $\left(20^{\circ} 1^{\prime} \mathrm{N}, 75^{\circ} 50^{\prime} \mathrm{W}\right)$, was used during the experiments carried out in July and October (2009). This dryer has a capacity of $0.3 \mathrm{~m}^{3}$, is equipped with a solar collector of $2 \mathrm{~m}^{2}$, a $12 \vee \mathrm{DC}$ fan, a chamber for drying, various metallic trays where samples of pine (Pinus sp.) wood were placed, a gate that controls the recirculation of air and a plenum chamber. The air comes into the dryer by one side, being heated in the roof, sucked into the plenum chamber and ducted to the fan which blows it into the drying chamber where the wood is placed on trays. Fig. 1 shows the air path inside the dryer and accross the stocked timber, highlighting the possibility of air recirculation. After passing through the trays, a percentage of the air exits from the underneath, the other fraction is recirculated towards the fan. The position of the hand regulated recirculation gate, was the same for both experiments $(50 \%$ open $)$.
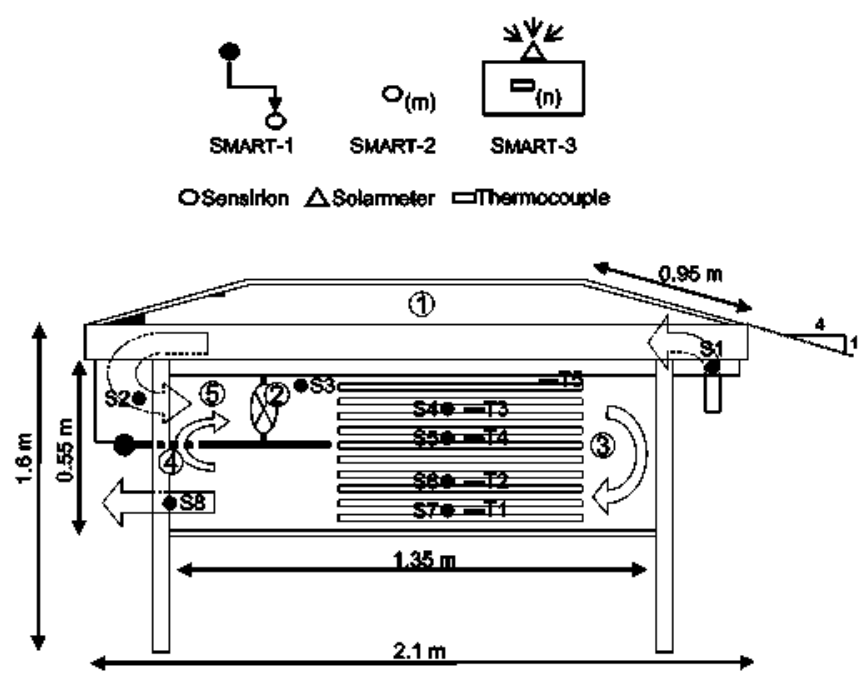

Fig. 1. (Up) Schematic representation of the proposed Smart sensors. Type and (number) of sensors required is presented. (down) Scheme of the solar dryer: solar collector (1), fan (2), chamber for drying (3), gate for recirculation of air (4), and plenum chamber (5). The arrows indicate the airflow. Also, the location of the eight Sensirion 51-58 (•) and the five thermocouples T1-T5 $(\square)$ is indicated.

\subsection{Experiments}

Two experiments are presented in this paper: one for the dynamic characterization of the air inside the dryer, while the second assesses the energy balance related to solar irradiation and daily timber temperature oscillation.

For the first experiment eight Sensirion sensors (see Fig. 1) were used to characterize the drying air at different positions in the dryer: at solar collector inlet and outlet ( $\mathrm{S} 1$ and $\mathrm{S2}$ ), at drying chamber inlet and outlet ( $S 3$ and $S 8$ ) and four locations between the wood planks (from \$4 to $\$ 7$ ). The sensors were connected by wire to a board with a Peripheral Interface Controller (PIC) as showing Fig. 2. In the PIC the signals were multiplexed and then sent to a computer via RS232. The Sensirion (SHT) is a single chip relative humidity and temperature multi-sensor module that delivers a calibrated digital output. The device includes a capacitive polymer sensing element for relative humidity (RH) and a band gap temperature sensor. Both are seamlessly coupled to a 14 bit analog to digital converter and a serial interface circuit on the same chip. Each SHT is individually calibrated in a precision humidity chamber. The calibration coefficients are programmed into the OTP (One Time Programmable) memory. These coefficients are used internally during measurements to calibrate the signals from the sensors. For temperatures significantly different from $25^{\circ} \mathrm{C}$, it is necessary to perform humidity compensation; the temperature coefficient of the RH sensor should be considered according to manufactured expressions. The diyer was full filled with wet wood and data were collected at day time (from 8 to $16 \mathrm{~h}$ approximately) along 5 days (480 data per sensor). No data collection was carried out during nights because instrumentation was dismantled every day due to the tropical storm risk in this season. The sample weight loss was measured at the end of each drying working day, using a precision electronic balance ADG10 (Adam Equipment $\mathrm{Co}$. Ltd., Heraeus, Madrid, precision $\pm 0.1 \mathrm{~g}$ ).

For the second experiment carried out in July, one sensirion sensor ( $\mathrm{S} 3$ in Fig. 1) was available as to characterize the drying air, together with a solarimeter (RD009 G.I.S. Jberica, resolution $1 \mathrm{~W} / \mathrm{m}^{2}$ and precision $\pm 10 \mathrm{~W} / \mathrm{m}^{2}$ ) for measuring the flux of solar radiation on solar panel and five thermocouples type $T$ 


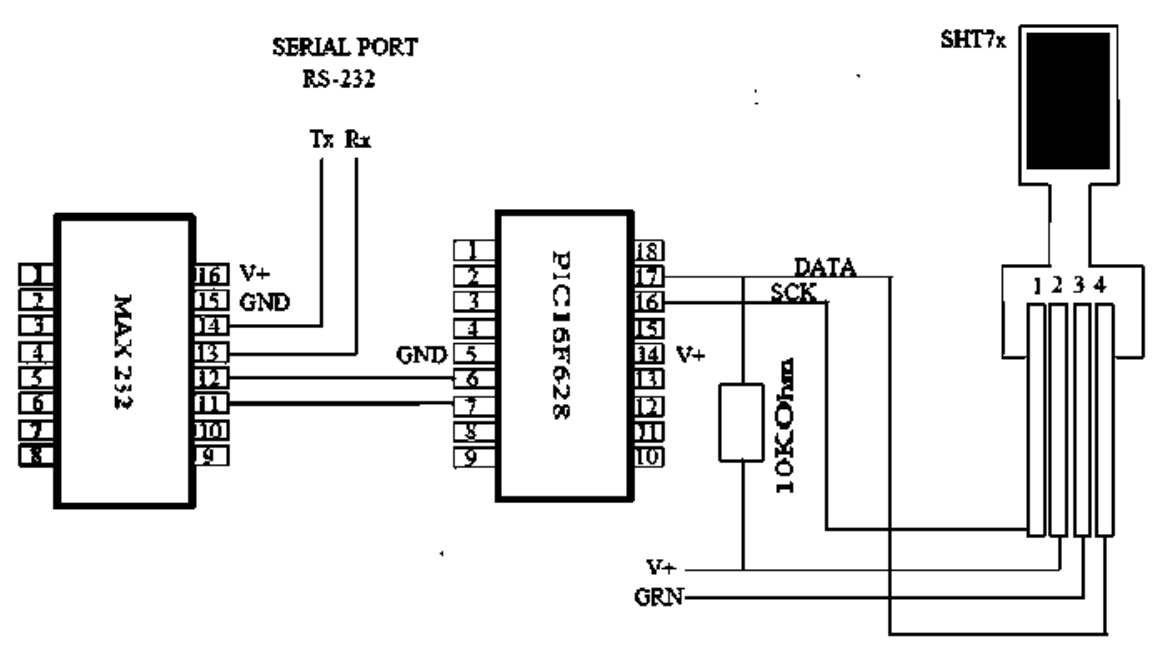

Fig. 2. Complete electronic diagram of the PIC system.

Table 1

Nomenclature in order of appearance in the text

\begin{tabular}{|c|c|c|}
\hline$H$ & Air absolut humidity & $\left(\mathrm{kg}_{\text {water }} \mathrm{kg}_{\text {dry air }}^{-1}\right)$ \\
\hline$\tau$ & Air temperature & $(\mathrm{K})$ \\
\hline$V_{s}$ & Specific air volume & $\left(\mathrm{mair}_{\mathrm{air}}^{3} \mathrm{~kg}_{\mathrm{dry} \text { air }}^{-1}\right)$ \\
\hline$Q$ & Flux of ventilator & $\left(m^{3} s^{-1}\right)$ \\
\hline$t$ & Time & (s) \\
\hline$M$ & Wood moisture & $\left(\mathrm{kg}_{\text {water }} \mathrm{kg}_{\mathrm{dry} \text { wood }}^{-1}\right)$ \\
\hline$A$ & Wood drying area & $\left(\mathrm{m}^{2}\right)$ \\
\hline$m_{\mathrm{dry}}$ & Wood dry mass & $(\mathrm{kg})$ \\
\hline quap & Latent heat of vaporization of wood water & $\left(\mathrm{J} \mathrm{kg}^{-1}\right)$ \\
\hline$\sigma$ & Convection heat transfer coefficient & $\left(\mathrm{W} \mathrm{m}^{-2} \mathrm{~K}^{-1}\right)$ \\
\hline 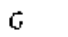 & Mass flux density of the air & $\left(\mathrm{kg}_{\text {air }} \mathrm{m}^{-2} \mathrm{~s}^{-1}\right)$ \\
\hline$s$ & Cross section for air circulation & $\left(m^{2}\right)$ \\
\hline$L$ & Half thickness of timber & (m) \\
\hline$D$ & Effective diffusion coefficient & $\left(m^{2} s^{-1}\right)$ \\
\hline$D_{0}$ & Reference diffusion coefficient & $\left(m^{2} s^{-1}\right)$ \\
\hline$E_{\mathrm{a}}$ & Activation energy & $\left(\mathrm{Jg}^{-1}\right)$ \\
\hline$R$ & Universal gas constant & $\left(\mathrm{J} \mathrm{kg}^{-1} \mathrm{~K}^{-1}\right)$ \\
\hline$T$ & Absolute temperature of wood & (K) \\
\hline$E$ & Energy & (J) \\
\hline$C_{p}$ & Heat capacity of wood & $\left(\mathrm{J} \mathrm{kg}^{-1} \mathrm{~K}^{-1}\right)$ \\
\hline$C_{p O}$ & Heat capacity of the oven dry wood & $\left(\mathrm{J} \mathrm{kg}^{-1} \mathrm{~K}^{-1}\right)$ \\
\hline$C_{p}^{\text {water }}$ & Heat capacity of water & $\left(\mathrm{J} \mathrm{kg}^{-1} \mathrm{~K}^{-1}\right)$ \\
\hline$A_{\mathrm{c}}$ & Aditional energy in the wood-water bond & $\left(\mathrm{Jkg}^{-1} \mathrm{~K}^{-1}\right)$ \\
\hline 9 & Energy per mass unit & $\left(\mathrm{J} \mathrm{kg}^{-1}\right)$ \\
\hline$h$ & Enthalpy & $\left(J \mathrm{~kg}^{-1}\right)$ \\
\hline$S$ & Surface of the dryer solar panel & $\left(m^{2}\right)$ \\
\hline Prad & Radiation density power & $\left(\mathrm{Wm}^{-2}\right)$ \\
\hline$\dot{\xi}$ & Eficiency & \\
\hline \multicolumn{3}{|c|}{ Subscripts } \\
\hline w & Wet bulb & \\
\hline FSP & Fiber saturation point & \\
\hline e & Equilibrium & \\
\hline 0 & Initial & \\
\hline$v$ & Vapor & \\
\hline 1 & Saturated liquid & \\
\hline
\end{tabular}

(copper-constantan), installed on wood planks, for measuring wood temperatures. Fig. 1 shows the position of the termocouples. $\mathrm{T} 5$ is located on wood with maximum exposure to drying, and sensors distribution corresponding to T1-T4 termocouples responds to the supervision in regions with obstacles for air circulation. Type $\mathrm{T}$ thermocouples are suited for measurements in the $-200^{\circ} \mathrm{C}$ to $350^{\circ} \mathrm{C}$ range. Since both conductors are non-magnetic, there is no Curje point and thus no abrupt change in characteristics. Type $T$ thermocouples have a sensitivity of about $43 \mu \mathrm{V} /{ }^{\circ} \mathrm{C}$. The dryer was full filled with wet wood and data were collected continously during $72 \mathrm{~h}$ ( 7223 data per thermocouple).

\subsection{Psychrometric model}

The ASAE D271.2, defined in April 1979 and reviewed in 2005 (ASABE Standards, 2006), was used for computing the psychrometric properties of the air in the dryer. This standard enables the calculation of all psychrometric data of air whenever two independent psychrometric properties of an air-water vapor mixture are known in addition to the atmospheric pressure. A network with eight sensors provides air temperature and relative humidity in eight critical points in the dryer. Absolute humidity $\mathrm{H}$ (water mass over dry air mass), wet bulb humidity $H_{w}$ (water mass over dry air mass), wet bulb temperature (the temperature of a volume of air cooled adiabatically to saturation by evaporation of retained water) $\tau_{w}$, specific volume $V_{s}$ (air volume over dry air mass) and specific enthalpy $h$ (enthalpy over dry air mass), characterized the air at each point (see Fig. 3 ). See nomenclature at Table 1.

\subsection{Mass bolance model: Smart-1}

Two out of the eight Sensirion sensors were considered for this purpose (see Fig. 1): one located at the drying chamber inlet (after mixing with the recirculation air, S3 in Fig. 1), and the other one at the dryer outlet (S8 in Fig. 1). The estimation of the extracted water from the timber along each working day according the absolute humidity increase in the air is the basis of the 5MART-1, the simplest smart sensor proposed in this work. The difference of absolute humidity of the air between the outlet $H_{\text {out }}$ and the inlet $H_{\text {in }}$ is considered to be the extracted water $H_{\text {ext }}$ (see Fig. 4). At each time $t$ the mass of extracted water per mass unit of dry air is computed according to

$H_{\text {ext }}=H_{\text {out }}-H_{\text {in }}$.

Considering the air density as the inverse of the specific volume, and the flux of ventilator $Q$ (see Table 3 ), the rate of wood water extracted is computed as

$\frac{d H_{\mathrm{ext}}}{d t}=-\frac{1}{V_{s}(t)} \mathrm{QH} H_{\mathrm{ext}}(t)$.

The numerical integration of the previous expression based on the finite differences method, allows us to estimate the water loss of 


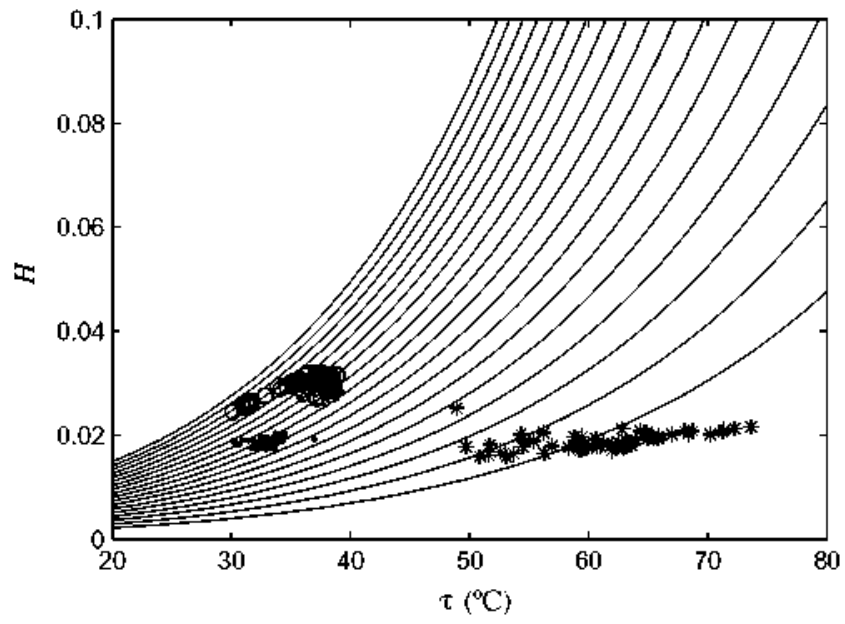

Fig. 3. Psychrometric chart, air temperature $\tau$ versus absolute humidity $H$, for three Sensirion sensors located at solar collector inlet (.) and outlet (*), and dryer outlet (o) along 1 day data recording for Experiment 1. Time interval of 5 min was used between consecutive measurements. Contour plots represent lines of constant relative humidity of the air from $15 \%$ to $100 \%$

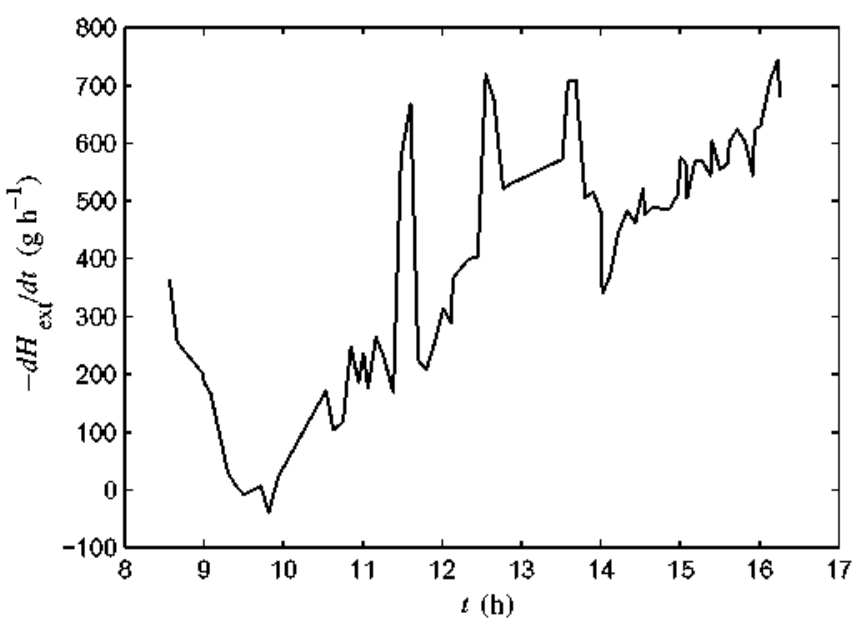

Fig. 4. Rate of wood water extracted $-d H_{\text {exd }} / d t$ along one drying day.

the wood for each working day. The accumulated water extracted along the complete drying cycle was compared with the reference measurements, based on gravimetric determination (see Fig. 5).

\subsection{Dynamical model: Smart-2}

It is possible to define a model based sensor that relays on the diffusion kinetics by means of assesing temperature and relative humidity of the air inside the kiln, in this case measured for the net of eight Sensirion sensors (see Fig. 1). This smart sensor will allow to determine the drying rate and the timber moisture distribution inside the dryer.

The drying rate expressed as $-d M / d t$, where $M$ is the oven dry wood moisture (water mass over oven dry wood mass), allows identifying two different kinetics: one with a constant drying rate, for surface moisture $M_{\mathrm{s}}$ above the fiber saturation point $M_{\mathrm{FSp}}$, and a second one for surface moisture below the $M_{\mathrm{FSp}}$ value, characterized for a decreasing drying rate.

For $M_{S} \geqslant M_{\mathrm{FSP}}$, it is considered that the transient moisture diffusion through a wood sample (a porous and hygroscopic material) is quick enough to maintain a layer of free water in the wood-air interface. It is possible to define a state where the convection heat transfer and water mass transfer occur, from the wood surface to the hot and dry air, with a constant drying rate. The diying process depends, as external parameters, only on the temperature and the absolute humidity of the drying air. Geankoplis (1983) proposed the heat and mass transfer balances that allow to define the constant drying rate as

$-\frac{d M}{d t}=\frac{A \sigma\left(\tau-\tau_{w}\right)}{m_{\mathrm{dry}} q_{\mathrm{vap}}}$

where the difference between the dry air $\tau$ and wet bulb $\tau_{w}$ temperatures acts as the impulsive force of this process, $A$ is the drying area, $m_{\mathrm{dry}}$ is the dry mass of the timber, and $q_{\text {vap }}$ is the latent heat of vaporization of wood water per mass unit at the temperature $\tau_{\mathrm{w}}$. Magnitude $\sigma$ is the convection heat transfer coefficient of the air, again defined by Geankoplis (1983) as $\sigma=k G$, where $G$ is the mass flux density of the air, calculated as $G=Q(1+H) / s V_{s}$, being $Q$ the flux of the ventilator, $H$ absolute humidity, $s$ the cross section for drying air circulation, and $V_{5}$ the specific volume (see coefficients in Table 3).

In a solar dryer, continuous changing surrounding conditions $(H$ and tof the drying air) in the drying chamber during drying process are observed due to transient variation of weather parameters. The model implementation as a time depending Matlab routine, allows us to recalculate continuously the $-d M / d t$. The numerical integration of $-d M / d t$ based on the finite differences method provides the timber moisture at the eight locations of Sensirion inside the kiln for this first drying period.

Table 2

Description of the proposed mathematical models.

\begin{tabular}{|c|c|c|c|}
\hline & SMART-1 & SMART-2 & SMART-3 \\
\hline Type of model & Empirical & Analytical & Analytical \\
\hline $\begin{array}{l}\text { Estimated } \\
\text { magnitudes }\end{array}$ & Wood Moisture (M) & Wood Moisture $(M)$ & $\begin{array}{l}\text { Energy efficiency of dryer }(c) \text { and } \\
\text { wood moisture }(M)\end{array}$ \\
\hline $\begin{array}{l}\text { Measured } \\
\text { magnitudes }\end{array}$ & $\begin{array}{l}\text { Temperature }(\tau) \text { and relative } \\
\text { humidity }(R H) \text { of the air at dryer } \\
\text { inlet and outlet }\end{array}$ & $\begin{array}{l}\text { Temperature }(\tau) \text { and relative humidity }(R H) \text { of local air at } m \text { positions } \\
\text { inside the kiln }\end{array}$ & $\begin{array}{l}\text { Solar radiation }\left(P_{\mathrm{rad}}\right) \text { and local } \\
\text { wood temperature }(T) \text { at in } \\
\text { positions }\end{array}$ \\
\hline $\begin{array}{l}\text { Type (and number) } \\
\text { of sensors }\end{array}$ & Sensirion (2) & Sensirion $(\mathrm{m})$ & Solarmeter and thermocouple $(\mathrm{n})$ \\
\hline $\begin{array}{l}\text { Parameters in the } \\
\text { model }\end{array}$ & None & Reference diffusion coefficient $\left(D_{0}\right)$ and activation energy $\left(E_{\mathrm{a}}\right)$ & $\begin{array}{l}\text { Energy of the wood-water bond } \\
\text { (qbond) }\end{array}$ \\
\hline Input arguments & $\begin{array}{l}\text { Air flow inside the dryer }(Q) \text { and } \\
\text { initial wood moisture }\left(M_{0}\right)\end{array}$ & $\begin{array}{l}\text { Drying wood area }(A) \text {, dry mass of the timber }\left(m_{d r y}\right) \text {, cross section for } \\
\text { drying ail circulation }(s) \text {. initial wood moisture }\left(M_{0}\right) \text { and half thickness } \\
\text { of timber }(L)\end{array}$ & $\begin{array}{l}\text { Daily initial and final wood } \\
\text { moisture }(M) \text { and diy mass of the } \\
\left.\text { timber ( } m_{\text {dry }}\right)\end{array}$ \\
\hline $\begin{array}{l}\text { Need of feed-back } \\
\text { from other } \\
\text { Smart sensors }\end{array}$ & No & No & $\begin{array}{l}\text { Yes: daily initial and final wood } \\
\text { moisture from SMART-1 and/or } \\
\text { SMART-2 }\end{array}$ \\
\hline
\end{tabular}


Table 3

Parameters and input arguments for the equations used in the model skiki-2. ( $\dagger$ ) Values reported for softwoods as the pine one (Smith and Langrish, 2008).

\begin{tabular}{llll}
$A$ & $7 \mathrm{~m}^{2}$ & $M_{0}$ & 0.6 \\
$m_{\text {dry }}$ & $60 \mathrm{~kg}$ & $i$ & $0.0125 \mathrm{~m}$ \\
$Q$ & $0.11 \mathrm{~m}^{3} \mathrm{~s}^{-1}$ & ${ }^{+} D_{0}$ & $0.000130 \mathrm{~m}^{2} \mathrm{~s}^{-1}$ \\
$s$ & $0.004 \mathrm{~m}^{2}$ & ${ }^{+} E_{\text {+ }}$ & $1776.297 \mathrm{~kJ} \mathrm{~kg}^{-1}$ \\
$k$ & 14278 & $R$ & $0.4615 \mathrm{~kg} \mathrm{~kg}^{-1} \mathrm{~K}^{-1}$ \\
$\zeta$ & 0.8 & & \\
\hline
\end{tabular}

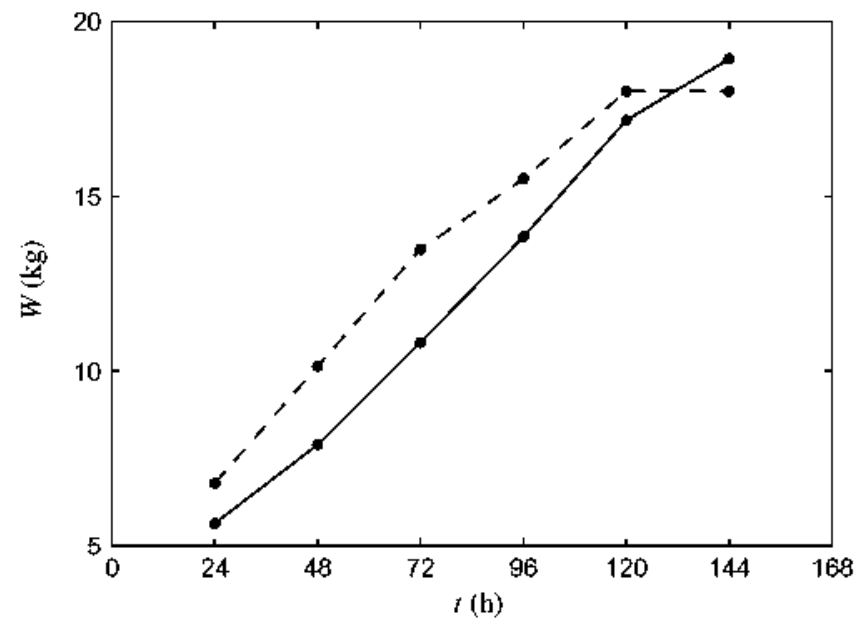

Fig. 5. Accumulated wood water ( $W$ ) extracted along a complete diying cycle estimated with SMAKT-1 (solid line) and gravimetric experimental measurement (dashed line).

For $M_{\mathrm{s}} \leqslant M_{\mathrm{FSP}}$, diffusion is the mechanism that govern a decreasing drying rate at this stage (Khater et al., 2004). There are many methods used to calculate drying diffusion, the most common being the solution of Fick's law (Crank, 1979; Luikov, 1968) for an infinite plate (one-dimensional problem), assuming that the moisture transport is primarily by diffusion with no external mass transfer limitation and that shrinkage is negligible

$\frac{M(t)-M_{\mathrm{e}}}{M_{0}-M_{\mathrm{e}}}=\frac{8}{\pi^{2}} \sum_{n=1}^{\infty} \frac{1}{(2 n-1)^{2}} \times \exp \left(-\left(\frac{(2 n-1) \pi}{2 L}\right)^{2} D t\right)$.

Equation above expresses the dimensionless timber moisture, where $M(t)$ and $M_{0}$ are the averaged wood moisture content at any time $t$ and $t=0$ respectively. $M_{e}$ is the equilibrium moisture content at timber surface that can be taken to be negligible because it assumed a dry hot air surrounding that avoid to stay water at timber surface making the values of $M_{e}$ relatively small compared to $M(t)$ and $M_{0} . L$ is the half thickness of timber, and $D$ represents the temperature dependent diffusion coefficient defined by the Arrhenius equation

$D=D_{0} \exp \left(-\frac{E_{\mathrm{a}}}{R T}\right)$

where $D_{0}$ is the reference diffusion coefficient, $E_{a}$ is the activation energy, $R$ is the universal gas constant (see coefficients in Table 3) and $T$ is the absolute temperature of wood taking into account that for this second drying period it has been consider negligible the difference between $T$ and $\tau$.

The equation that enable the drying rate calculation at low moisture content, taking into account that the diffusivity will depend on time since drying temperature varies according to it, is given by the following expression obtained as the derivative with respect to time of the first term $n=1$ in the expansion of Eq. 4:

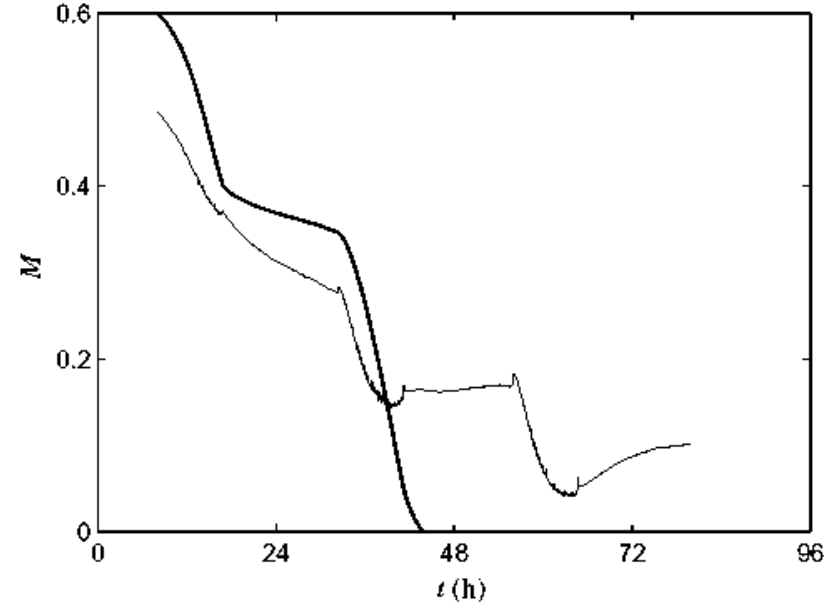

Fig. 6. Evolution of oven dry wood moisture $M$ along one drying cycle for $M_{\mathrm{s}} \geqslant M_{\mathrm{FSP}}$ (thick line) and for $M_{\mathrm{s}} \leqslant M_{\mathrm{FS} r}$ (thin line), corresponding to one Sensirion sensor (S3 in Experiment 1) located inside the kiln.

$-\frac{d M}{d t}=\frac{2 M_{0}}{L^{2}}\left(t \frac{d D}{d t}+D\right) \exp \left(-\left(\frac{\pi}{2 L}\right)^{2} D t\right)$

The SMART-2 model is defined for the combined resolution of Eqs. 3, 5, and 6 that allow to recalculate in real time a changeable drying rate (see Fig. 7) according with the temperature and absolute humidity of the air measured with the Sensirion in different positions inside the kiln. The integrated forms of these equations provides the evolution of wood moisture content for the constant drying rate and the decreasing drying rate kinetics (see Fig. 6).

\subsection{Energy balance model: Smart-3}

We can define a model based sensor regarding the temperature distribution data of the wood inside the dryer and also thesolar radiation values. The temperature data are obtained from a suitable arrangement of thermocouples (a very low cost sensor) placed over the wood and distributed into the dryer (see Fig. 1). This smart sensor will provide us the wood moisture distribution into the dryer and the energy efficiency of the drying process.

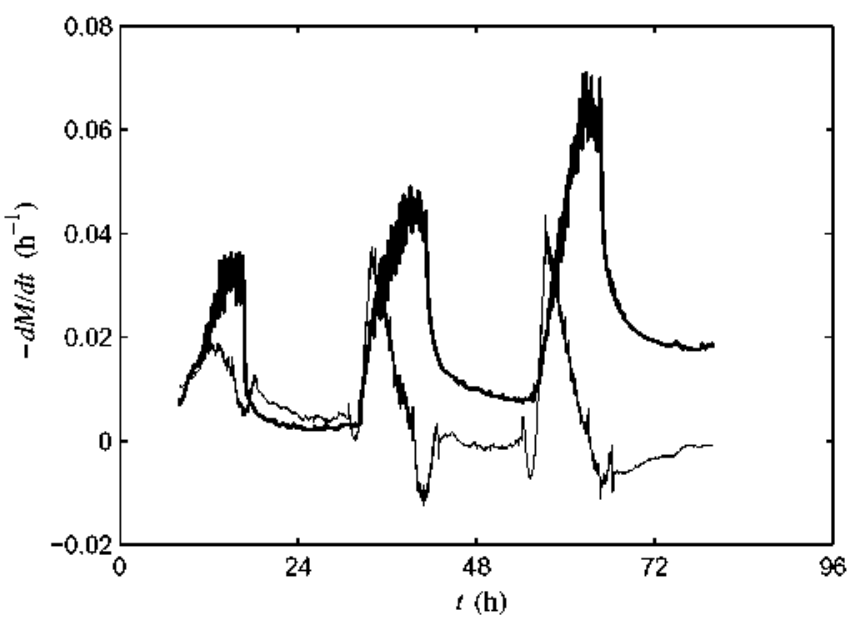

Fig. 7. Evolution of drying rate along one drying cycle for two different kinetics: one with a constant diying rate (thick line) and the other one with a decreasing drying late (thin line). The first intercept point marks the critical point. Data corresponding to one Sensirion sensor ( 53 in Experiment 1 ) located inside the kiln. 

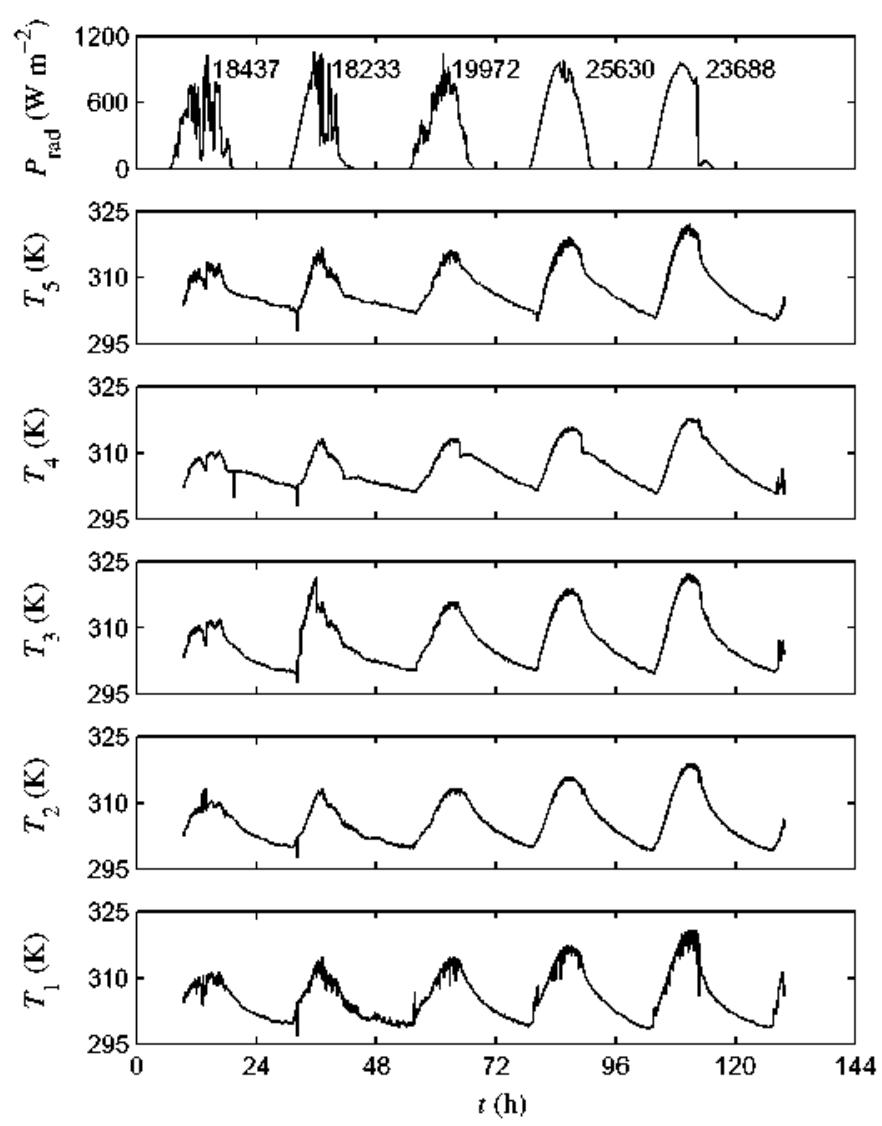

Fig. 8. (Top panel) Density of power of the solar radiation $P_{\text {rad }}$ along five solar cycles. Time starts at 00:00 on the first day of drying. The density of energy corresponding to every cycle has been indicated in $\mathrm{kJ} \mathrm{m}^{-2}$ units. (All other panels) Temperature data of the five thermocouples $T_{1}-T_{5}$ along the same five solar cycles. Note the increasing maximum temperature throughout the drying process.

As shown in Fig. 8, for each daily cycle we have essentially, neglected short time oscillations, ${ }^{1}$ and assessed a minimum temperature corresponding to night cooling, and a maximum temperature due to the solar midday. The minimum temperature was approximately the same for every cycle. However, although the solar radiation was similar every day in this experiment, the maximum temperature increases for each cycle.

This behavior can be understood by means of a simple energy balance and considering the thermodynamics of the dry process. We can consider that the solar radiation energy $E_{\text {rad }}$ is used to heat the wood ( $\left.E_{\text {heat }}\right)$ and evaporate the water $\left(E_{\text {yap }}\right)$, namely

$E_{\text {rad }}=E_{\text {beat }}+E_{\text {vap }}+E_{\text {loss }}$,

where $E_{\text {loss }}$ represents the energy losses. Since the wood moisture decreases for successive cycles, and the wood heat capacity also decreases when the wood moisture decreases, the same energy will produce a greater temperature for successive cycles. Moreover, due to the wood moisture decreasing, the amount of evaporated water will be less for successive cycles, then the water vaporization energy will be less too, and a greater amount of energy will be used to heat the wood.

The heat capacity of wood $C_{p}$ can be expressed as a function of the oven dry wood moisture $M$ and wood temperature $T$ (see Forest Products Laboratory, 1999, Ch. 3)

\footnotetext{
${ }^{1}$ In order to determine the global minimum and maximum temperatures for each daily cycle, we have made a data smoothing by means of a least squares high degree polynomial fit of the themocouples data.
}

Table 4

Coefficients for the expressions of the heat capacity of wood used in the model SMinRT-3, and validity interval (Forest Products Laboratory, 1999, Ch. 3).

\begin{tabular}{llll}
\hline$C_{D}^{\text {water }}$ & $4.19 \mathrm{~kJ} \mathrm{~kg}^{-1} \mathrm{~K}^{-1}$ & $b_{1}$ & $-6.191 \mathrm{~kJ} \mathrm{~kg}^{-1} \mathrm{~K}^{-1}$ \\
$\mathbf{a}_{1}$ & $0.1031 \mathrm{~kJ} \mathrm{~kg}^{-1} \mathrm{~K}^{-1}$ & $b_{2}$ & $0.0236 \mathrm{~kJ} \mathrm{~kg}^{-1}$ \\
$\mathbf{a}_{2}$ & $0.003867 \mathrm{~kJ} \mathrm{~kg}^{-1}$ & $b_{3}$ & $-1.33 \mathrm{~kJ} \mathrm{~kg}^{-1} \mathrm{~K}^{-1}$ \\
& & $280 \leqslant T \leqslant 420(\mathrm{~K})$ & \\
\hline
\end{tabular}

$C_{p}=\frac{C_{p 0}(T)+M \cdot C_{p}^{\text {water }}}{1+M}+A_{c}(M, T)$,

where $C_{p 0}(T)$ is the heat capacity of the oven dry wood, $C_{p}^{\text {water }}$ is the heat capacity of the water, and $A_{c}(M, T)$ is an additional term that accounts for the additional energy in the wood-water bond. The heat capacity of oven dry wood follows a linear dependence with temperature

$C_{p 0}(T)=a_{1}+a_{2} T$,

and the additional term can be expressed as

$A_{c}(M, T)=\left\{\begin{array}{lll}M\left(b_{1}+b_{2} T+b_{3} M\right) & \text { if } M \leqslant M_{\mathrm{FSP}} \\ 0 & \text { if } M>M_{\mathrm{FSP}}\end{array}\right.$,

being $M_{\mathrm{FSP}} \approx 0.3$ the moisture corresponding to the fiber saturation point. If the moisture is below $M_{\mathrm{FSP}}$ then all molecules of water are bounded to wood, else there is free water. The numerical values of the coefficients above are represented in Table 4.

Considering the definition of the heat capacity, that is $C_{p}=(\partial q)$ $\partial T)_{p}$, we can integrate Eq. 8 between the minimum temperature $T_{\min }$ and maximum temperature $T_{\max }$ for every daily cycle, obtaining an expression for the energy (per mass unit) $q_{\text {heat }}=E_{\text {heat }} / m_{\text {heat }}$ needed for the heating

$$
\begin{aligned}
q_{\text {heat }}= & {\left[\frac{1}{1+M}\left(M \cdot C_{p}^{\text {water }}+a_{1}+\frac{a_{2}}{2} \Sigma T\right)\right.} \\
& \left.+M\left(b_{1}+\frac{b_{2}}{2} \Sigma T+M b_{3}\right)\right] \Delta T
\end{aligned}
$$

being $\Sigma T=T_{\max }+T_{\min }$ and $\Delta T=T_{\max }-T_{\min }$. Reorganizing this expression we can obtain a polynomial in the variable moisture

$A M^{3}+B M^{2}+C M+D=0$,

where $\quad A=b_{3} \Delta T, \quad B=\left(b_{1}+b_{2} \Sigma T / 2+b_{3}\right) \Delta T, \quad C=\left(C_{p}^{\text {water }}+b_{1}+\right.$ $\left.b_{2} \Sigma T / 2\right) \Delta T-q_{\text {heat }}$, and $D=\left(a_{1}+a_{2} \Sigma T / 2\right) \Delta T-q_{\text {heat }}$. The root of this polynomial with physical meaning will give us the wood moisture. Similarly, we can obtain a polynomial in the variable temperature

$A^{\prime} T_{\max }^{2}+B^{\prime} T_{\max }+C^{\prime}=0$

where $A^{\prime}=\left[a_{2}+b_{2}(1+M) M\right] / 2, \quad B^{\prime}=a_{1}+M\left[C_{p}^{\text {water }}+(1+M) \cdot\left(b_{1}+\right.\right.$ $\left.\left.b_{3} M\right)\right]$, and $C=-\left[\left(A^{\prime} T_{\min }+B^{\prime}\right) T_{\min }+(1+M) q_{\text {heat }}\right]$. The positive root of this polynomial will give us the maximum temperature.

Summarizing, in the wood heating process, we have a relationship between the four variables $f\left(q_{\text {heal }}, M, T_{\text {min }}, T_{\max }\right)=0$, so that we can express one of them as a function of the three others. Notice that this relationship has the property $f\left(q_{\text {heat }}, M, T_{\min }, T_{\max }\right)=$ $f\left(-q_{\text {heat }}, M, T_{\max }, T_{\min }\right)$.

On the other hand, we have the energy used to evaporate the water. This energy corresponds to the enthalpy (or latent heat) of vaporization plus, if no fiber saturation, the energy of the woodwater bond. Using the ASHRAE data for the refrigerant R-718 (water/steam) (see ASHRAE, 2005, p. 20.37), we can obtain the enthalpy of vaporization for a temperature $T$ as the difference between the enthalpy of saturated vapor $h_{\mathrm{y}}(T)$ and saturated liquid $h_{1}(T)$. So that, we can obtain the energy of vaporization (per mass unit) $q_{\text {vap }}=E_{\text {vap }} / m_{\text {vap }}$ as an average of the enthalpy of vaporization in the interval of temperatures corresponding to the minimum and 


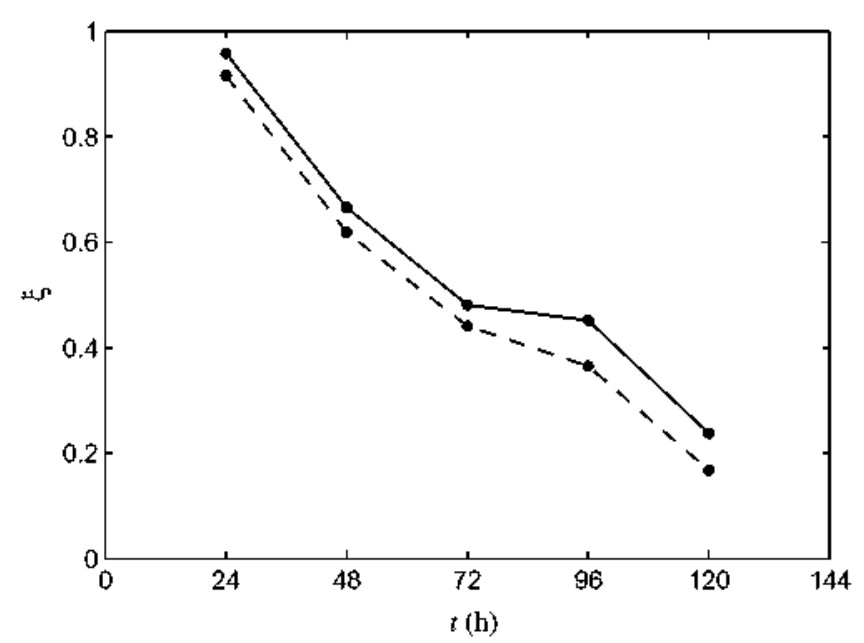

Fig. 9. Evolution of the total energy efficiency $\bar{\zeta}_{\text {total }}$ (solid line) and vaporization energy efficiency $\zeta_{\text {vap }}$ (dashed line) of the diyer throughout the diying process.

maximum temperature of each daily cycle, plus a term corresponding to the energy of the wood-water bond

$q_{\mathrm{vap}}=\frac{1}{T_{\max }-T_{\min }} \int_{T_{\min }}^{T_{\max }} d T\left[h_{\mathrm{v}}(T)-h_{\mathrm{I}}(T)\right]+q_{\text {bond }}$.

where
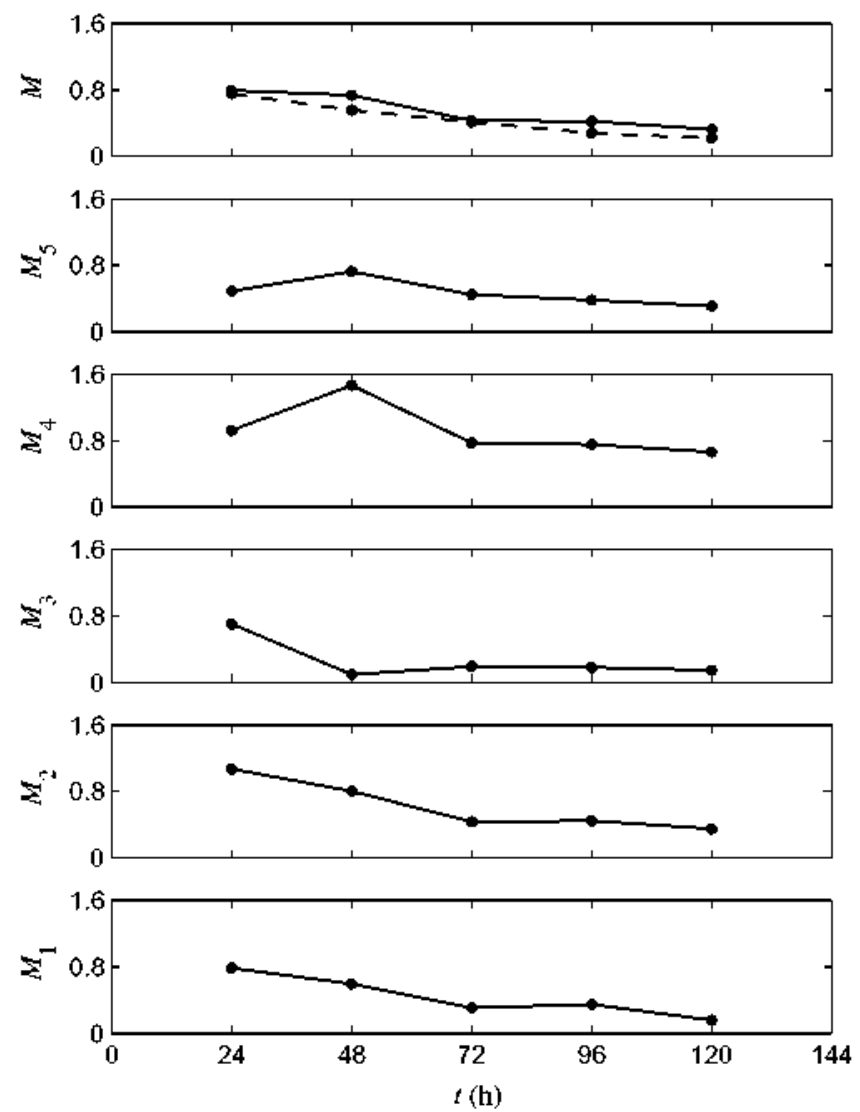

Fig. 10. (Top panel) Time evolution of the average of the wood moisture calculated for each thermocouple position (solid line) and experimental wood moisture (dashed line). (All other panels) Time evolution of the wood moisture estimated for each thermocouple position $M_{1}-M_{5}$ corresponding to the temperature data $T_{1}-T_{5}$ in Fig. 8. $q_{\text {bond }}=\left\{\begin{array}{lll}316.32 \mathrm{~kJ} \mathrm{~kg}^{-1} & \text { if } & M \leqslant M_{\mathrm{FSP}} \\ 0 & \text { if } & M>M_{\mathrm{FSP}}\end{array}\right.$

is the wood-water bond energy (see Briggs, 1994, Ch. 9).

Finally, we need the solar radiation data [density of power $P_{\text {rad }}(t)$ ] provided by a meteorological station (see Fig. 8) to compute the solar energy received by the dryer along each daily cycle. Namely,

$E_{\text {rad }}=S \int_{t_{1}}^{t_{2}} d t P_{\text {rad }}(t)$

where $S$ is the surface of the dryer solar panel, and $\left(t_{1}, t_{2}\right)$ is the time interval corresponding to a solar cycle.

The information supplied by this model SMART-3, together with that of models SMART-1 and SMART-2, allows us to calculate the total energy efficiency of the dryer $\xi_{\text {total }}=\left(E_{\text {heat }}+E_{\text {vap }}\right) / E_{\text {rad }}$, and the vaporization energy efficiency $\xi_{\text {vap }}=E_{\text {vap }} / E_{\text {rad, }}$ as can be see in Fig. 9.

Moreover, it is possible to estimate the moisture distribution into the dryer associated to the position of each thermocouple (see Fig. 10). For this purpose, the averaged minimum and maximum temperatures are used to obtain the value of the heating energy, then this value is used in order to estimate the moisture for every thermocouple.

\section{Results and discussion}

The implementation of the psychrometric model in a ad hoc Matlab rontine, allows supervising in real time the drying air conditions in different points. In Fig. 3 environmental conditions can be observed through the Sensirion sensor located at solar collector inlet. Sensirion sensor located at collector outlet defines the drying air as a hot (varying from $50^{\circ}$ to $75^{\circ} \mathrm{C}$ ) and dry $(\mathrm{H} \approx 0.015)$ air mass. After drying process air experiments a decrease in the temperature and an increase in the absolute humidity, reaching in certain moments the saturation conditions.

Three SMART model based sensors are proposed in this work (see Table 2 and Fig. 11). The simplest smart sensor, SMART-1, using only two Sensirion sensors, allows to estimate the accumulated water extracted from wood along a complete drying cycle with a correla-
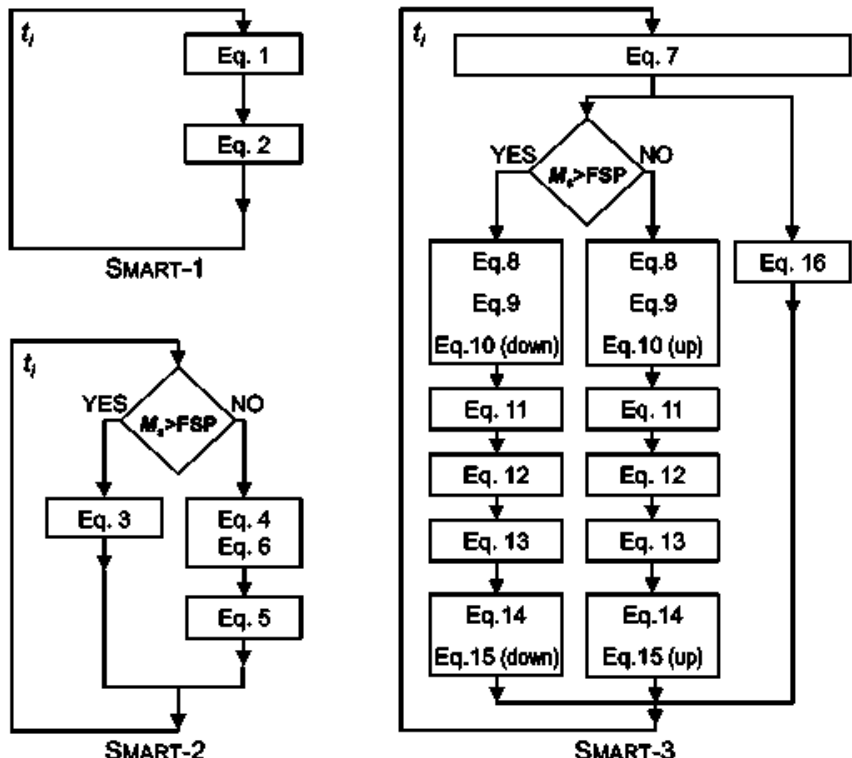

Fig. 11. Flowchart of the equations implemented for SMAKT-1, SMART-2 and SMART-3 models. 
Table 5

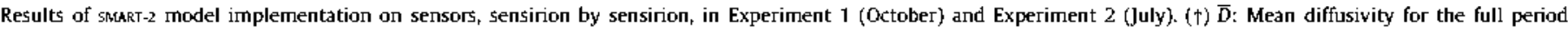
correspoding to each experiment; $t_{c t}$ : time for the end of the constant drying rate period; $t_{d c}$ : time for the beginning of the decreasing drying rate period.

\begin{tabular}{|c|c|c|c|c|c|c|}
\hline & s3(EXP.2) & S3(EXP.1) & S4(EXP.1) & SE(EXP.1) & S6(EXP.1) & $57($ EXP.1) \\
\hline$+\bar{D} \times 10^{-10}$ & $5.14 \pm 1.00$ & $5.12 \pm 1.02$ & $5.00 \pm 1.01$ & $4.60 \pm 0.88$ & $5.12 \pm 1.04$ & $5.21 \pm 1.07$ \\
\hline $\mathrm{t}(\mathrm{h})$ for Fourier $>0.2$ & 16.89 & 16.95 & 17.36 & 18.87 & 16.95 & 16.66 \\
\hline$M_{0}$ & 0.6 & 0.8 & 0.8 & 0.8 & 0.8 & 0.8 \\
\hline${ }^{\dagger} \mathbf{t}_{c t}(h)$ & 18 & 30 & 52.5 & - & 30.5 & 30 \\
\hline $\mathrm{M}$ at $\mathrm{t}_{\mathrm{ct}}$ & 0.38 & 0.48 & 0.4 & - & 0.48 & 0.49 \\
\hline${ }^{\dagger} t_{d c}(h)$ & 32 & 53.5 & 75 & - & 54.4 & 51 \\
\hline$M$ at $t_{d c}$ & 0.28 & 0.33 & 0.28 & - & 0.32 & 0.31 \\
\hline
\end{tabular}

tion coefficient of 0.97 (a root mean squared error of $1.89 \mathrm{~kg}$ and mean bias error (MBE) of $1.52 \mathrm{~kg}$ ) compared to the gravimetric experimental measurement (see Fig. 5). The MBE obtained indicates an over-stimation of the extracted water by SMART-1. That could be explained considering that higher relative humidity during the night (due to lower temperatures and the disconnection of the fun at evening-night time for experiment 2) could increase the moisture content of the wood. Such increases (or sample weight gain) were not taken into account in the gravimetrically measurements, that were only carried out once at the end of each drying day.

Table 5 shows as the implementation of SMART-2 model allows to determine the diffusivity (see Eq. 5), being the average value of $D$ for the drying cycle studied equal to $5.14 \times 10^{-10} \mathrm{~m}^{2} \mathrm{~s}^{-1}$ in July and equal to $5.12 \times 10^{-10} \mathrm{~m}^{2} \mathrm{~s}^{-1}$ in October for the same sensor S3, values in the same order of magnitude as are shown by (Janjai et al., 2010) for soft woods. The Fick's law solution described in the literature (Crank, 1979; Luikov, 1968) establishes that for a Fourier number $D t / L^{2}>0.2$, the infinite series solution in Eq. 4 can be approximated by the first term $n=1$ of the series (Tripathy and Kumar, 2009). So in this study the diffusion process which dominates the drying process of softwoods at low moisture contents will be correctly estimated for drying times higher than $17 \mathrm{~h}$ (see Table $5)$. In the 5MART-2 model the point where the two drying kinetics (constant and decreasing drying rates) coincide, it is considered as the critical point which establishes the end of the constant drying rate period and the beginning of the decreasing drying rate one (Fito et al., 2001). Fig. 7 shows that for the drying cycle studied this occurs after an initial period of constant drying rate of $18 \mathrm{~h}$ for \$3 in Experiment 2. ln Fig. 6 averaged wood $M$ value of 0.38 corresponds at this stage with the instant where $M_{s}=M_{\mathrm{FSP}}$. The drying period from $M_{S}=M_{\mathrm{FSP}}$ to reach the $M_{\mathrm{FSP}}$ at wood center is considered as a transition drying period. This period, from 18 to 32 drying hours in this work, is characterized by a similar behaviour of the constant and decreasing drying rates estimated (see Fig. 7). Literature stablishes a reference value for $\boldsymbol{M}_{\mathrm{FSP}}$ of 0.3 (Fernández-Golfín and Conde, 2007) and Table 5 shows that the average $M$ wood content at this stage ranged from 0.28 to 0.33 . The end of this transition period marks the clear beginning of the diffusion phenomenon. The higher initial moisture content in wood planks of Experiment 1 compared to that in Experiment 2 (0.8vs 0.6) determines a longer initial constant drying period (30 vs $18 \mathrm{~h}$ for the same sensor position (S3)). The multidistributed supervision of the dryer in Experiment 1 shows up the lack of uniformity in drying conditions supported by the wood planks located in the inner or center of the drying chamber ( 55 position (see Fig. 1)) versus the wood planks externally situated (corresponding to S3 and S7 sensor positions). The highest difusivity values in the second case (see Table 5) make progress the decreasing drying rate period, while in the center mainly the highest air humidity registered by S5 determines that the constant drying rate kinetics predominate in this area of the drying chamber. The identification of these drying periods not only allows the correct estimation of $M$ and $-d M / d t$ as a function of the drying kinetics but also will allow to program specific dryer regulations for each dryer area, period and weather conditions.

Moreover, as we can see in Fig. 9, the model SMART-3 indicates a decreasing efficiency along the drying process from 0.9 to 0.2 . This fact is due to the well known effect of efficiency fall as the moisture decreases (Fernández-Golfin and Conde, 2007). However, we can observe a recuperation of the efficiency between the third and fourth drying cycles (72-96 h). This recovery seems to correspond to the inhomogeneous drying of the wood (see Fig. 10). Notice that the moisture corresponding to the position of the thermocouples T4 and T5 increases between the first and second drying cycles (24-48 h), and the moisture also increases slightly at the position of the thermocouple $\mathrm{T} 3$ between the second and third cycles $(48-72 \mathrm{~h}$ ). The location of thermocouples into the dryer is shown in Fig. 1. Further experiments are required to verify this correspondence and to design a control strategy (by means of the fan velocity and the recirculation gate) in order to improve the energy efficiency. Undoubtedly, a more homogeneous drying will improve the energy efficiency and also the quality of the wood.

\section{Conclusions}

The operation and decision making in most dryers systems is guided by highly empiric recipes and rules which are usually too rigid to adapt the operation to sudden changes in the process conditions, specially important in solar dryers. The implementation of these three proposed models on embedded electronics and wireless sensor networks will turn into smart sensors, where data corresponding to the temperature and relative humidity of the air inside the kiln collected by Sensirion sensors and wood temperature data from thermocouples, allow to estimate the most important and complex parameters in thermal drying as drying rate and wood moisture in real time.

\section{Acknowledgments}

The funding of this work has been covered by Comunidad de Madrid through TAGRALIA-CM research group, Technical University of Madrid, by the AECID program through A/019197/08 and A/9586/07 projects and by the MICINN with the project SmartQC (GL2008-05267-C03-03).

\section{References}

ASABE Standards, 2006. Psychrometric Data ASAE D271.1 APR1979, R2005, 5t. Joseph, Ml.

ASHRAE, 2005. Handbook-Fundamentals (\$l), American Society of Heating. Refrigeration, and Air-Conditioning Engineers, Atlanta.

Briggs, D., 1994. Forest Products Measurements and Conversion Factors, University of Washington, Institute of Forest Resources, Seattle.

Camilli, A., Cugnnasca, C.E., Saraiva, A.M., Hirakawa, A.R., Corrêa, P.L.P., 2007. From wireless sensors to field mapping: anatomy of an application for precision agriculture. Computers and Electronics in Agriculture 58, 25-36. 
Chen, H., Hernandez, C.E., Huang. T., 2005, A study of the drying effect on lemon slices using a closed-type solar dryer. Solar Energy 78, 97-103.

Corsi, C., 2007. Smart sensor's. Infrared Physics and Technology 49, 192-197.

Crank, J., 1979. The Mathematics of diffusion. Clarendon Press.

Cunha, C.R. Peres, E., Morais, R. Oliveira, A.A. Matos, S.G. Fernandes, M.A., Ferreira, P.J.5.G. Reis, M.J.C.S., 2010. The use of mobile devices with multi-tag technologies for an overall contextualized vineyard management. Computers and Electronics in Agriculture 73, 154-164.

Fargali, H.M., Nafeh, A.A., Fahmy, F.H., Hassan, M.A., 2008. Medicinal herb drying using a photovoltaic array and a solar thermal system. Solar Energy 82, 1154-1160.

Fernández-Golfin, J.]. Conde, M., 2007. Manual técnico de secado de maderas, Asociación de lnvestigación Técnica de las lndustrias de la Madera y el Corcho (AITIM), Madrid.

Fito, P., Andrés, A.M., Barat, J.M. Albors, A.M., 2001. Introducción al secado de alimentos por aire caliente, 2001-1092. Departamento de Tecnología de los Alimentos, Universidad Politécnica de Valencia, Valencia.

Forest Products Laboratory, 1999. Wood handbook, FPL-GTR-113, US Department of Agriculture. Forest Service. Forest Products laboratory. Madison.

Geankoplis, C.J., 1983. Drying of Process Materials Transport Processes and Unit Operations. Allyin and Bacon, Boston.

Haque, M.N., langrish. T.A.G., 2005. Assessment of the actual performance of an industrial solar kiln for drying timber. Drying Technology 23 (7), 1541-1553.

Janjai, S., Intawee, P., Kaewkiew, J., 2010. A solar timber drying system; experimenta performance and system modeling. International Energy Journal 11, 131-144.

Khater, H.A., Helwa, N.H., Enayet, M.M., Hashish, M.l., 2004. Optimization of solar kiln for drying wood. Drying Technology 22 (4), 677-701.

Kitchen, N.R., 2008. Emerging technologies for real-time and integrated agriculture decisions. Computers and Electronics in Agriculture 61, 1-3.

luikov, A.V. 1968. Analytical Heat Diffusion Theory, University of Illinois Department of Energy Engineering, Illinois.

luna, D., Nadeau. J.P., Jannot, Y., 2009. Solar timber kilns: state of the art and foreseeable developments. Renewable and Sustainable Energy Reviews 13 , 1446-1455.

Matese, A., Di Gennaro, S.F., Zaldei, A., Genesio, l, Vaccari, F.P., 2009. A wireless sensor network for precision viticulture: the NAV system. Computers and Electronics in Agriculture 69, 51-58.
Nadimi, E.S., Sogaard, H.T., Bak, T., Oudshoorn, F.W., 2008. ZigBee-based wireless sensor networks for monitoring animal presence and pasture time in a strip of new grass. Computers and Electronics in Agriculture 61, 79-87.

Reuss, M., Benkert, S., Aeberhard, A., Martina, P., Raush, G., Rentzell, B.V., Sogari, N. 1997. Modelling and experimental investigation of a pilot plant for solar wood diying. Solar Energy 59 (4-6), 259-270.

Smith, S.A., Langrish, A.G., 2008. Multicomponent solid modeling of continuous and intermittent drying of Pinus radiata sapwood below the fiber saturation point. Drying Technology 26, 844-854.

Son, J.D., Niu, G., Yang. B.S., Hwang. D.H., Kang. D.S., 2009. Development of smart sensor's system for machine fault diagnosis. Expert Systems with Applications 36 (9), 11981-11991.

Sorensen, C.G., Pesonen, 1., Fountas, 5., Suomi, P., Bochtis, D., Bildsøe, P., Pedersen, S.M., 2010. A user-centric approach for information modelling in arable farming. Computers and Electronics in Agriculture 73, 44-55.

Spencer, B.F., Ruiz-Sandoval, M.E., Kurata, N., 2004, Smart sensing technology: opportunities and challenges. Joumal of Structural Control and Health Monitoring 11 (4), 349-368.

Togersen, F.A, Skjøth, F., Munksgaard, L., Højsgaard, S., 2010. Wireless indoor tracking network based on Kalman filters with an application to monitoring dairy cows. Computers and Electronics in Agriculture 72, 119-126.

Tripathy, P.P., Kumar, S., 2009. A methodology for detemination of temperature dependent mass transfer coefficients form drying kinetics: application to solar drying. Journal of Food Engineering 90, 212-218.

Umstätter, C., Waterhouse, A., Holland, J.P., 2008. An automated sensor-based method of simple behavioural classification of sheep in extensive systems. Computers and Electronics in Agriculture 64, 19-26.

Vellidis, G., Tucker, M., Perry, C., Kvien, C., Bednarz, C., 2008. A real-time wireless smart sensor array for scheduling irrigation. Computers and Electronics in Agriculture $61,44-50$.

Wharton, P.S., Kirk, W.W. Baker, K.M., Duynslager, 1., 2008. A web-based interactive system for risk management of potato late blight in Michigan. Computers and Electronics in Agriculture 61, 136-148.

Zhu, X., Li, D., He, D., Wang. J., Ma, D., Li, F., 2010. A remote wireless system for water quality online monitoring in intensive fish culture. Computers and Electronics in Agriculture 71, \$3-\$9. 